\title{
Development of Design Methodology for a Small Solar-Powered Unmanned Aerial Vehicle
}

\author{
Parvathy Rajendran $\mathbb{D}^{1}$ and Howard Smith ${ }^{2}$ \\ ${ }^{1}$ School of Aerospace Engineering, Universiti Sains Malaysia, Penang, Malaysia \\ ${ }^{2}$ Aircraft Design Group, School of Aerospace, Transport and Manufacture Engineering, Cranfield University, Cranfield, UK \\ Correspondence should be addressed to Parvathy Rajendran; aeparvathy@usm.my
}

Received 7 August 2017; Revised 4 January 2018; Accepted 14 January 2018; Published 27 March 2018

Academic Editor: Mauro Pontani

Copyright (C) 2018 Parvathy Rajendran and Howard Smith. This is an open access article distributed under the Creative Commons Attribution License, which permits unrestricted use, distribution, and reproduction in any medium, provided the original work is properly cited.

\begin{abstract}
Existing mathematical design models for small solar-powered electric unmanned aerial vehicles (UAVs) only focus on mass, performance, and aerodynamic analyses. Presently, UAV designs have low endurance. The current study aims to improve the shortcomings of existing UAV design models. Three new design aspects (i.e., electric propulsion, sensitivity, and trend analysis), three improved design properties (i.e., mass, aerodynamics, and mission profile), and a design feature (i.e., solar irradiance) are incorporated to enhance the existing small solar UAV design model. A design validation experiment established that the use of the proposed mathematical design model may at least improve power consumption-to-take-off mass ratio by $25 \%$ than that of previously designed UAVs. UAVs powered by solar (solar and battery) and nonsolar (battery-only) energy were also compared, showing that nonsolar UAVs can generally carry more payloads at a particular time and place than solar UAVs with sufficient endurance requirement. The investigation also identified that the payload results in the highest effect on the maximum take-off weight, followed by the battery, structure, and propulsion weight with the three new design aspects (i.e., electric propulsion, sensitivity, and trend analysis) for sizing consideration to optimize UAV designs.
\end{abstract}

\section{Introduction}

In recent years, awareness of the potential of unmanned aerial vehicles (UAVs) for multiple missions has increased the level of research into improving UAV design and technologies. Studies found that electric- or fossil fuel-powered UAVs have inadequate flying hours for various tasks. Increased focus has been placed recently on developing hybrid-powered electric UAVs, especially with the combination of solar energy and battery or fuel cells in a batterypowered system. The current study considers the pros and cons of various power systems [1-6] and examines the design and development of solar cells in battery-powered UAVs.

For more than a decade, small solar- and battery-powered electric UAVs were the subject of research and development [1, 5-19]. Seven small solar UAVs (i.e., So Long, Sky-Sailor, Sun-Sailor, Sun Surfer, AtlantikSolar AS-2, University of Minnesota's SUAV, and Cranfield University's Solar UAV) weighing less than $20 \mathrm{~kg}$ have been developed to date. As a prominent researcher in this field, Noth $[14,20]$ developed a mathematical design model for sizing solar-powered electric UAVs. However, this mathematical design model focuses only on the conceptual design stage in estimating the general sizing of UAV configurations.

Noth $[14,20]$ focused on the 3 sizing elements of mass, aerodynamics, and performance. Design characteristics, such as aircraft power consumption and cruise speed, must also be optimized to ensure that the required long endurance of the UAVs for 24 hours of real surveillance and mapping applications is achieved. The current study aims to improve the design properties, which requires further in-depth work, such as solar irradiance, mission profile, and aerodynamic characteristics. Research gaps in electric propulsion sizing, sensitivity studies, and trend analysis have also been identified.

A synthesized UAV mathematical design model suitable for sizing and configuration design of small solar-powered and battery-powered electric systems was developed to fulfill 


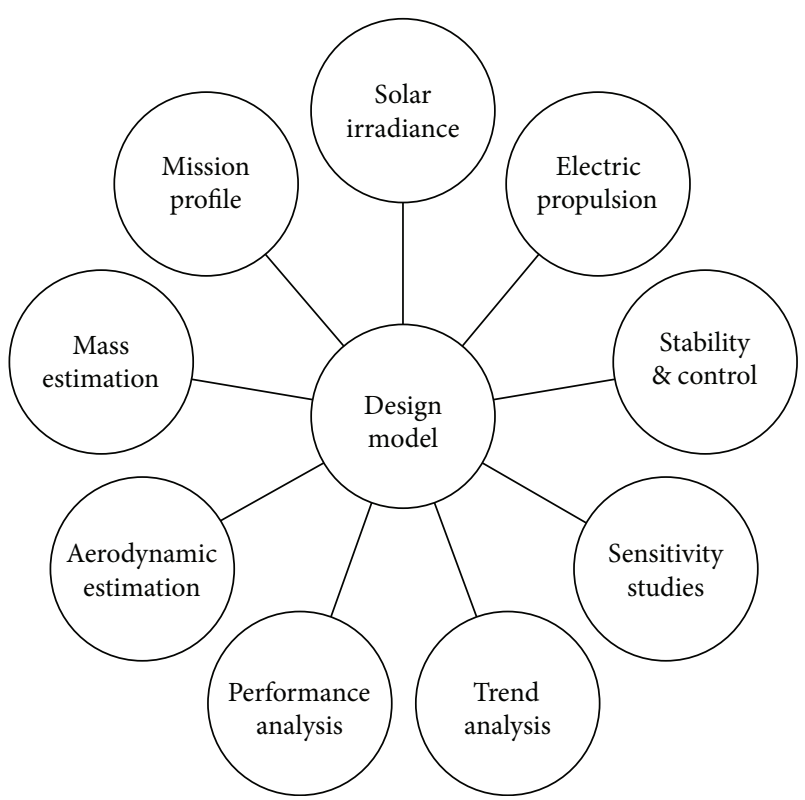

FIGURE 1: Solar-powered electric UAV design element.

the previously mentioned requirements. This comprehensive expansion work, based on various studies [21-23], considers nine design properties (i.e., mass sizing, aerodynamics, performance, stability and control, mission profile, solar irradiance, electric propulsion, sensitivity studies, and trend analysis) to improve the current design model.

The proposed mathematical model was initially quasivalidated using existing UAV data via rigorous computer modeling and analyses. The validity of the mathematical model was deemed satisfactory after achieving a lower error in the model's conceptual design than in the actual UAV design using the empirical database. An actual solarpowered electric UAV [1] was also designed, developed, and flight-tested to further quasi-validate this model. The comprehensive design model is developed in this study to further minimize assumptions and simplify previous designs.

\section{Mathematical Design Model}

The developed solar-powered electric UAV mathematical design model and its algorithm flowchart are illustrated in Figures 1 and 2, respectively. The model contains the nine design components mentioned earlier. Three design components, namely, mass estimation, aerodynamic estimation, and performance analysis, were initially developed by Noth [14]. Performance analysis is the only design component that was maintained based on the specifications developed by Noth.

In the mass estimation, the study by Mueller et al. [22] was further adopted. The component mass was divided into the following basic elements, namely, structure, battery, solar, electric propulsion, control system, and payload, as shown in (1), respectively. The aircraft's total take-off weight $\left(W_{\text {TOmax }}\right)$ may be expressed as a combination of the empty weight and payload weight, as shown in (2), respectively,

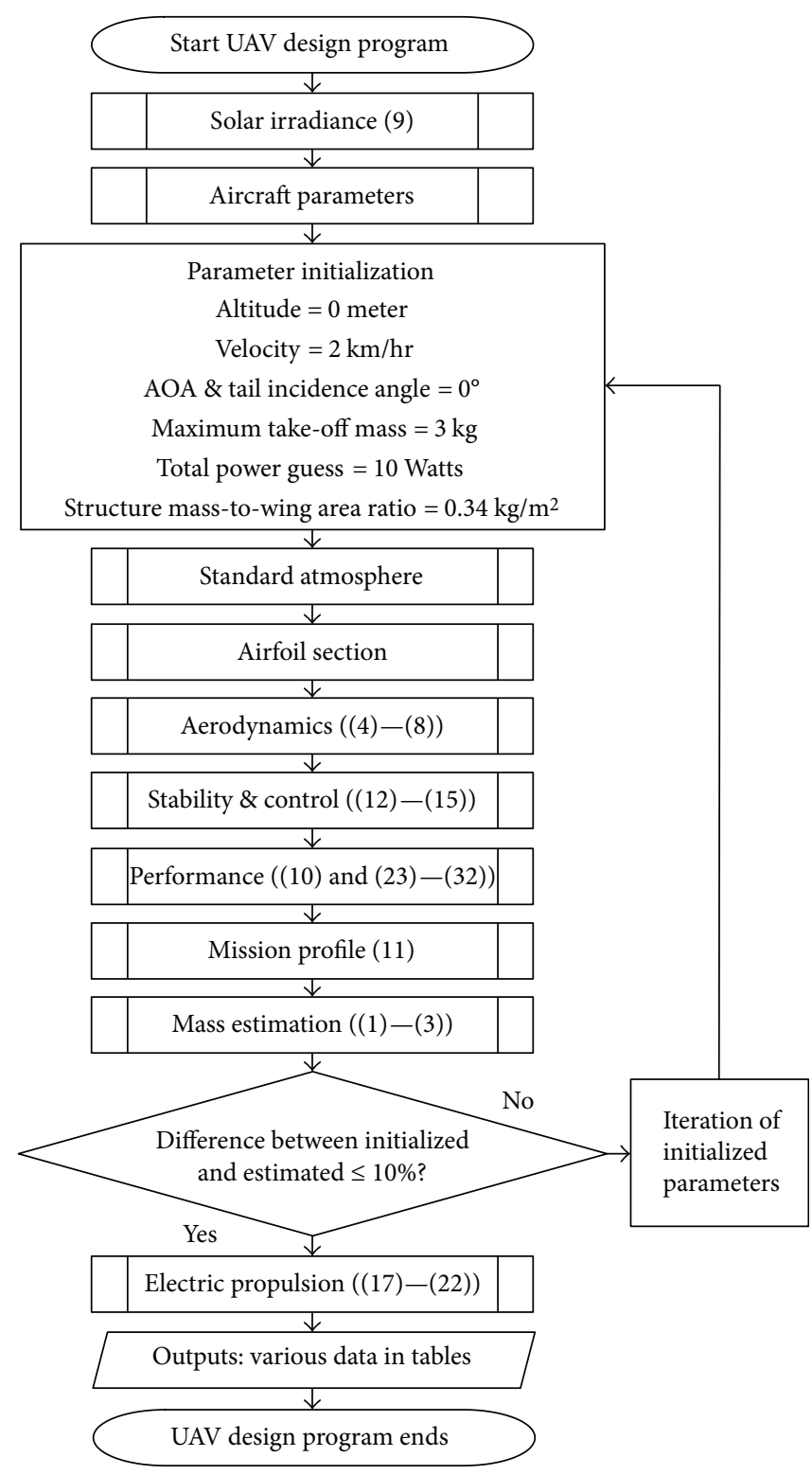

FIgURE 2: UAV design algorithm flowchart.

because a pure electric UAV does not have a variable weight during flight.

$$
\begin{aligned}
W_{\text {TOmax }}= & W_{\text {Struct }}+W_{\text {Batt }}+W_{\text {Solar }}+W_{\text {Electric }} \\
& +W_{\text {Ctrl }}+W_{\text {Pay_Max }} \\
W_{\text {TOmax }}= & W_{\text {Empty }}+W_{\text {Pay_Max }} .
\end{aligned}
$$

The relevant coefficient in predicting the empty weight of an electric UAV that weighs less than $15 \mathrm{~kg}$ is given in (3). This equation is determined using regression analysis by collecting all possible measurements of 83 small electric UAVs. These 83 small UAVs, including solar-, battery-, fuel cell-, and hydrogen-powered electric UAVs, weigh less than $14 \mathrm{~kg}$. The parameters gathered include weights, wing area $(S)$, wing span $(b)$, aspect ratio (AR), height, total length, root, and tip chord length of both the wing and tail surfaces. 


$$
W_{\text {Empty }}=0.79 \times b^{18.9012} S^{-9.4755} \mathrm{AR}^{-9.4558} W_{\mathrm{TOmax}}^{0.99} .
$$

Similarly, in aerodynamic estimation, specific lift and drag coefficient estimation was performed based on various wing and horizontal tail airfoil characteristics [21]. However, the fuselage and vertical tail characteristics have yet to be incorporated in this study. Additional power is incorporated into the mission power requirement, specifically by defining the maximum power consumption during maneuver $\left(P_{\text {Maneuver }}\right)$ at total mission power, compensating for the drag increment that remains unaccounted due to the fuselage and vertical tail.

The Reynolds number (RN) is a major factor in aerodynamic analysis. The $\mathrm{RN}$ range for an aircraft depends on the mean aerodynamic chord length $(c)$, airspeed $(V)$, air density $(\rho)$, and viscosity $(\mu)$. Equation (4) [21] defines the relation between these parameters.

$$
\mathrm{RN}=\frac{V c \rho}{\mu} .
$$

The aerodynamic submodel also predicts the lift coefficient by using a well-known theoretical estimation [21], as shown in (5). In level flight, the aircraft lift is equal to the take-off weight. Because the air density, airspeed, and wing area are known, the lift coefficient, $C_{L}$, may be estimated.

$$
C_{L}=\frac{L}{1 / 2 \rho V^{2} S}=\frac{W_{\mathrm{TOmax}}}{1 / 2 \rho V^{2} S} .
$$

The drag coefficient $C_{D}$ can be estimated using (6) [21], where the aircraft zero-lift-drag coefficient $C_{\text {Do }}$ can be obtained from the airfoil polar data at each RN. A linear interpolation is performed on these airfoil data to obtain $C_{\text {Do }}$ for a specific $R N$, angle of attack, and airspeed of an aircraft. Again, the vertical tail and fuselage drag component were not accounted since most high-endurance and lightweight UAVs have narrow fuselage. In addition, most of these UAVs are hand-launched, thus without a landing gear.

$$
C_{D}=C_{\text {Do_W }}+C_{\text {Di_W }}+C_{\text {Do_HT }}+C_{\text {Di_HT }} .
$$

Then, with the $C_{L}$ calculated at each $\mathrm{RN}$ using (4) earlier, the lift and drag may also be determined using

$$
\begin{aligned}
& L=\frac{1}{2} \rho V^{2} S C_{L}, \\
& D=\frac{1}{2} \rho V^{2} S C_{D} .
\end{aligned}
$$

Apart from the mass and aerodynamic estimation, the solar irradiance and mission profile were also incorporated. Integrations of these two design components have been detailed. Solar irradiance estimates include details such as specific time of the day, date of the year, and latitude and longitude coordinates [24] instead of a simplified average value of solar irradiance data for a particular day in a nearby major city. This estimation has enabled the prediction of the usability of a solar-powered aircraft in various parts of the world and its operation duration throughout the year.
The amount of solar irradiance $\left(\operatorname{Ir}_{\max }\right)$ that strikes the Earth, as given in (9), is critical in designing a solarpowered UAV. The power available through the solar module facilitates the sufficiency of the solar energy harnessed for the power required. The equation is adopted from [23-27], which begins by determining the input parameters, including the day of the year, latitude, longitude, and altitude of the place of interest.

$\operatorname{Ir}_{\max }=\frac{(1+0.033 \cos (0.017203 \mathrm{DN}(\pi / 180))) \sin (\operatorname{SOLALT}(\pi / 180))}{3.6(1000 / 4.8708)}$.

No previous work has estimated in detail the UAV solar power usage of the mission profile (i.e., not only cruise but also the other mission profile phases, such as climb, loiter/ maneuver, and descent). The effects of gust wind speed and direction were disregarded. The power required $\left(P_{\text {Required }}\right)$ for a level flight determined by the definition of the wing area is shown in (10) [21]. This calculation has not taken into consideration the flight path angle, the efficiency of the electric propulsion system, and the additional power consumption of the aircraft from the control system and payload.

$$
P_{\text {Required }}=\frac{C_{D}}{C_{L}} \sqrt{\frac{2 \mathrm{AR}\left(W_{\mathrm{TOmax}}\right)^{3}}{\rho C_{L} b^{2}}} .
$$

The power consumption of each mission profile phase is determined based on the flight path angle, as proposed by Sherwin [28]. Detailed mission profile power sizing is crucial especially when designing an aircraft for high endurance. The percentage of time spent on a 24-hour mission during cruise may be higher in comparison with that on a one-hour mission. Regardless of mission endurance, the climb and descent phase is similar. Thus, an appropriate ratio portion of each mission profile phase has been considered which includes climb, cruise, maneuver, and descent, as shown in (11) in respective order, instead of assuming that the aircraft only flies in level flight. The time fraction defined is intended for a specific mission study. This mathematical design model is assumed to be applicable only for an unmanned aircraft without a landing gear to achieve maximum endurance or range by flying, primarily, in level flight.

$$
\begin{aligned}
P_{\text {Total-Mission }}= & \frac{0.1}{60} P_{\text {Climb }}+\frac{59.5}{60} P_{\text {Cruise }} \\
& +\frac{0.3}{60} P_{\text {Maneuver }}+\frac{0.1}{60} P_{\text {Descent }} .
\end{aligned}
$$

The stability and control analysis measures the tail plane and boom length to ensure that the UAV is statically stable. This design property ensures the viability of the overall aircraft design-sizing simulation results. Determining the stability and controllability of the designed UAV plays a significant role in developing a well-designed UAV. Only static stability and control have been considered in this research. No work has yet been done on aircraft dynamics, which is recommended for further studies. 
In the proposed method, the parameters evaluated are the center of gravity (i.e., cg) range, trimmed elevator deflection angle, and trimmed angle of attack. The airfoil moment coefficient data are obtained by linear interpolation, as performed in the aerodynamic estimation, to determine these parameters. With these values and tail area $\left(S_{\mathrm{HT}}\right)$ and tail moment arm length $\left(l_{\mathrm{HT}}\right)$, the tail volume ratio $\left(V_{\mathrm{HT}}\right)$ is estimated using (12). Also, the tail zero-lift-pitching moment coefficient $\left(C_{\mathrm{Mo} \_\mathrm{HT}}\right)$ is then estimated using (13) [21], where $C_{\mathrm{L} \alpha \_\mathrm{HT}}$ is the lift curve slope of the tail, $\varepsilon_{\mathrm{O}}$ is the downwash angle at zero lift, $i_{\mathrm{W}}$ is the wing incidence angle, and $i_{\mathrm{HT}}$ is the tail incidence angle.

$$
\begin{aligned}
V_{\mathrm{HT}} & =\frac{l_{\mathrm{HT}}}{c}\left(\frac{S_{\mathrm{HT}}}{S}\right), \\
C_{\mathrm{Mo} \_\mathrm{HT}} & =V_{\mathrm{HT}} C_{\mathrm{L} \alpha \_\mathrm{HT}}\left(\varepsilon_{\mathrm{o}}+i_{\mathrm{W}}+i_{\mathrm{HT}}\right) .
\end{aligned}
$$

The aircraft's trimmed angles of attack $\alpha_{\text {trim }}$ and elevator deflection angles elev $\mathrm{trim}_{\text {trim }}$ are estimated. The aircraft's zerolift-pitching moment coefficient $\left(C_{\mathrm{Mo}}\right)$ is first determined using (14) [21], where $C_{\mathrm{Mo} \_\mathrm{W}}$ is the wing zero-lift-pitching moment coefficient. The trimmed angle of attack and elevator deflection angle can be calculated using (15) and (16) [21], where $C_{\operatorname{Mcg} \alpha}$ is the moment coefficient curve slope. Determining the aircraft's trimmed angle of attack at various elevator deflection angles gives a guideline to the required elevator deflection angle range that is within the allowable airplane angle of attack. Determining the elevator deflection range guarantees controllability by avoiding excessive pitch up (which can lead to stall) and pitch down.

$$
\begin{aligned}
C_{\mathrm{Mo}} & =C_{\mathrm{Mo} \_\mathrm{W}}+C_{\mathrm{Mo} \_\mathrm{HT}}, \\
\alpha_{\text {trim }} & =\frac{C_{\mathrm{Mo}}}{C_{\mathrm{Mcg} \alpha}}, \\
\mathrm{elev}_{\text {trim }} & =\frac{C_{\mathrm{Mo}}+C_{\mathrm{Mcg} \alpha} \alpha_{\mathrm{W}}}{V_{\mathrm{HT}} C_{\mathrm{L} \alpha \_\mathrm{HT}}} .
\end{aligned}
$$

The current practices of propulsion system selection for common electrically driven UAVs are imprecise. This propulsion sizing process gets more complex in a solaraugmented UAV. Yet, UAV designers commonly use the standard combination sets of the electric motor, gearbox, electronic speed controller, propeller, and battery recommended by model aircraft part manufacturers or suppliers for a specific UAV weight range. This process typically yields a margin of approximately $25 \%$ between the lower and upper weight for a given standard combination set.

Multiple combination sets are recommended, clearly indicating the wide range of flexibility and combination applicable to a specific unmanned aircraft. Thus, preevaluated sets of electric propulsion systems are obviously suboptimal options for aircraft designers. Electric propulsion analysis has been developed to optimize aircraft power and combination selection (i.e., battery, electronic speed controller, and electric motor and propeller sizes) of the propulsion system based on the desired aircraft performance.
In the current work, the electric propulsion system sizing is given by [29]. The electric motor efficiency ( $\left.\mathrm{eff}_{\text {Motor }}\right)$ can be estimated using (17) where $P_{\text {Motor-Out }}$ is the power out of the motor and $P_{\text {Motor-In }}$ is the power into the motor from the battery. Then, the power from the electric motor to the propeller $\left(P_{\text {Prop-In }}\right)$ can be estimated using the motor voltage $\left(V_{\text {Motor }}\right)$ and motor current $\left(I_{\text {Motor }}\right)$ as shown in (18). Meanwhile, the required power from the propeller $\left(P_{\text {Prop-Req }}\right)$ based on the simulated propeller diameter (Diam) and pitch (Pitch) size and propeller revolution per minute (RPM) can be evaluated as given in (19).

$$
\begin{aligned}
\operatorname{eff}_{\text {Motor }} & =\frac{P_{\text {Motor-Out }}}{P_{\text {Motor-In }}} \\
P_{\text {Prop-In }} & =\operatorname{eff}_{\text {Motor }} V_{\text {Motor }} I_{\text {Motor }}, \\
P_{\text {Prop-Req }} & =\frac{0.5 \rho}{g}\left(\frac{\mathrm{RPM}}{60}\right)^{3}(0.0254 \text { Diam })^{4}(0.0254 \text { Pitch })
\end{aligned}
$$

Here, the error difference between the input and required propeller power can be determined, where within $\pm 10 \%$ is preferred. This error difference limits and ensures that a suitable range of the propeller is obtained. In addition, the ideal performance occurs when the pitching velocity of the propeller $\left(V_{\text {Prop-Pitch }}\right)$ given in $(20)$ should be within 2.5 and three times the aircraft stall speed [29]. The thrust of the propeller

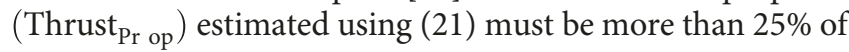
the maximum take-off mass of the UAV to have reasonable climb and acceleration capabilities.

$$
\begin{aligned}
V_{\text {Prop-Pitch }} & =\frac{\mathrm{RPM}}{60}(0.0254 \text { Pitch }) \\
\text { Thrust }_{\text {Prop }} & =\frac{P_{\text {Prop-Req }}}{g V_{\text {Prop-Pitch }}} .
\end{aligned}
$$

Once a list of a simulated propeller's diameter and pitch size combination has been produced with the criteria listed above, the optimized propeller size is chosen based on the least propeller tip static velocity $\left(V_{\text {Prop-Tip-Static }}\right)$. This velocity, estimated using (22), can provide the optimum propeller size combination for a better UAV performance in terms of high endurance and long range.

$$
V_{\text {Prop-Tip-Static }}=\pi \frac{\mathrm{RPM}}{60}(0.0254 \text { Diam }) .
$$

UAV performance analysis may be conducted to predict the effectiveness of the to-be-designed aircraft. The main performance criteria that are considered are velocity, stall velocity $\left(V_{\text {Stall }}\right)$, required thrust $\left(T_{\text {Required }}\right)$, available energy $\left(E_{\text {Available }}\right)$, and required power $\left(P_{\text {Required }}\right)$. The $V_{\text {maxCell }}$ is the maximum voltage of a battery cell, $S_{\text {Cell }}$ is the number of battery cells in series, $P_{\text {Cell }}$ is the number of battery cells in parallel, and $Q_{\text {Cell }}$ is the capacity of each battery cell. These performance analyses are computed using (23), (24), (25), (26), and (27) in respective order. 


$$
\begin{aligned}
V & =\sqrt{\frac{W_{\text {TOmax }}}{(1 / 2) \rho C_{L} S}}, \\
V_{\text {Stall }} & =\sqrt{\frac{W_{\text {TOmax }}}{(1 / 2) \rho C_{\text {Lmax } \_\mathrm{W}} S}} \\
T_{\text {Required }} & =\frac{W_{\text {TOmax }}}{C_{L} / C_{D}}, \\
E_{\text {Available }} & =V_{\text {max }_{\text {Cell }} S_{\text {Cell }} P_{\text {Cell }} Q_{\text {Cell }},} \\
P_{\text {Required }} & =T_{\text {Required }} V=\frac{C_{D}}{C_{L}} \sqrt{\frac{2 W_{\text {TOmax }} 3}{\rho C_{L} S} .}
\end{aligned}
$$

Stall velocity estimation is important prior to flight testing to prevent the aircraft from stalling. Ensuring that the available power is greater than the required power is crucial, not only for the aircraft to take-off and/or climb easily but for the anticipation of any gusts during flight. The excess available power $\left(P_{\text {Excess }}\right)$ can be estimated using (28) where the initial power of a mission $\left(P_{\mathrm{I}}\right.$ nitialise_Guess $)$ is guessed. This initial power will be iterated to ensure that the error difference between the initial guess and actual mission power (11) is within $\pm 10 \%$.

$$
P_{\text {Excess }}=P_{\text {Initialise_Guess }}-P_{\text {Required }} \text {. }
$$

The rate of climb and rate of optimal glide sink evaluation give a rough estimation of the required time to achieve the desired altitude. These parameters can be calculated using (29) and (30) in respective order [21].

$$
\begin{aligned}
\text { Rate of climb } & =\frac{P_{\text {Excess }}}{W_{\text {TOmax }}}, \\
\text { Rate of optimal glide sink } & =\frac{V}{L / D} .
\end{aligned}
$$

Finally, the aircraft's endurance and range are determined. These two variables of aircraft electric propulsion capability for solar and battery flight are identified using an assumption of no wind and estimated using (31) and (32) [23-27]. Studies will be conducted using the performance criteria trade and optimization. This process will improve the aircraft design configuration and optimize its capabilities.

$$
\begin{aligned}
\text { Endurance }_{\mathrm{S} \& \mathrm{~B}} & =\frac{E_{\text {Available }}}{P_{\text {Required }}}+0.7 t_{\text {Daylight }}, \\
\text { Range }_{S \& \mathrm{~B}} & =V \times \text { endurance }_{\mathrm{S} \& \mathrm{~B}} .
\end{aligned}
$$

In the mathematical design model, a new assessment scheme is developed to analyze the sensitivity of various parameters that exhibited the greatest and least effects on the UAV design. Evaluating how the entire design changes with parameter variations is important to ensure that the fidelity of specific models remains acceptable when change is introduced. Technologies were identified to considerably enhance the design or improve the system performance.

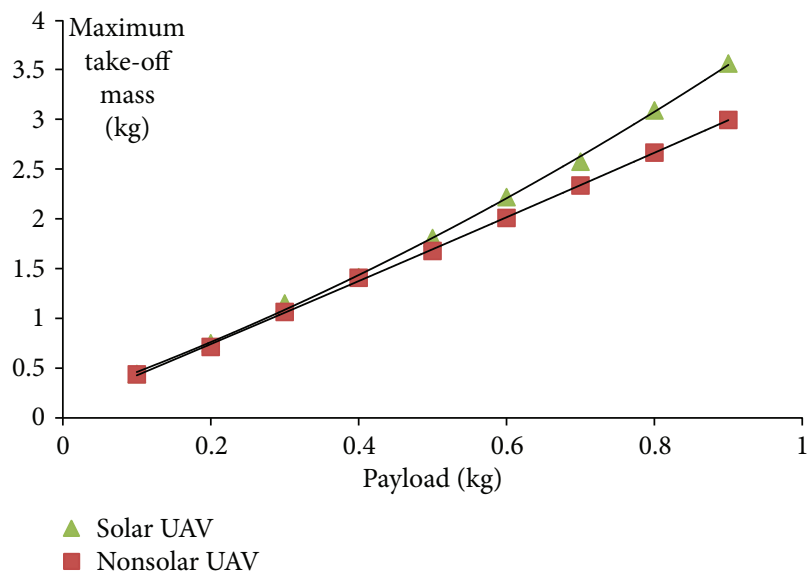

Figure 3: Payload versus maximum take-off mass of the solar and nonsolar UAVs.

Many components are evidently becoming smaller, more powerful, and more highly efficient than previous ones. A crucial approach is developed to assess the future trends in UAV designs. This approach evaluates the rate at which aircraft parts and component technologies are developing and projects their achievable or potential performance. The UAV mathematical design model can be used to identify the parts that have the most significant effect and that merit further research to yield the best prospects in UAV development.

\section{Result and Discussion}

A general analysis work was conducted on the mathematical design model that covers both solar (solar- and battery-powered) and nonsolar (battery-powered) UAV sizing. Although this design model can be used for design estimations for large UAVs, all calculations were explicitly focused on small handlaunchable UAVs weighing less than $4 \mathrm{~kg}$. The simulation was also subject to UAVs that can perform a minimum of 9 hours of flight operation beginning at 12 noon on 22 June 2014 at Cranfield, United Kingdom, with an iteration sizing accuracy of $1 \mathrm{~cm}$ or $1 \mathrm{~g}$.

Figure 3 shows the analysis results for both solar and nonsolar UAV configurations. The UAV take-off mass can be improved to sustain 9 hours of flight duration at a specified payload. The take-off mass of both solar and nonsolar UAVs nonlinearly increased with the payload. These nonlinear curves are mainly due to the dependence of the mass of the aircraft structure on the corresponding wing aspect ratio and span.

In this study, the feasible UAV design was restricted to the specified flight duration and payload. In this case, solar and nonsolar UAVs must have maximum take-off masses of $8.209 \mathrm{~kg}$ and $8.987 \mathrm{~kg}$, respectively, and must be capable of supporting payloads weighing $1.258 \mathrm{~kg}$ and $3.04 \mathrm{~kg}$, respectively, to achieve 9 hours of flight duration. The flight duration must be decreased to increase the payload or vice versa.

The relationship between the wing span and the mass of the structure at a constant payload of $0.35 \mathrm{~kg}$ and an aspect 


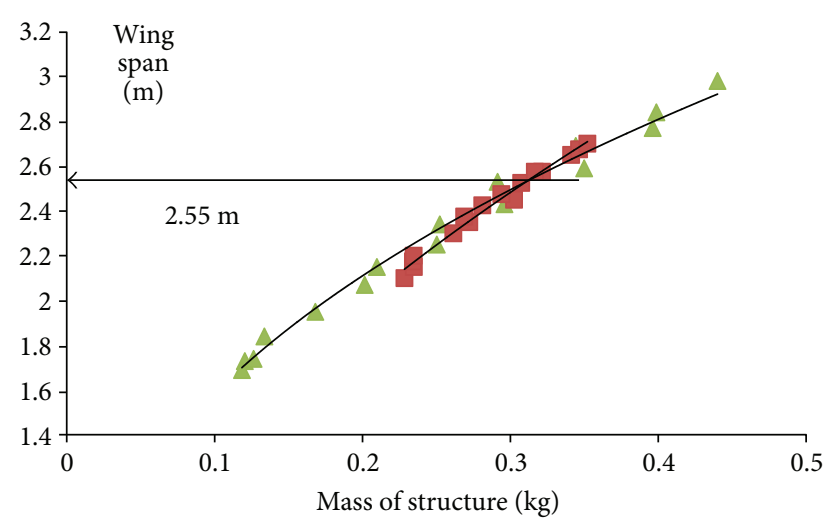

$\triangle$ Solar UAV

- Nonsolar UAV

FIGURE 4: Mass of the structure versus wing span of the solar and nonsolar UAVs at $0.35 \mathrm{~kg}$ payload.

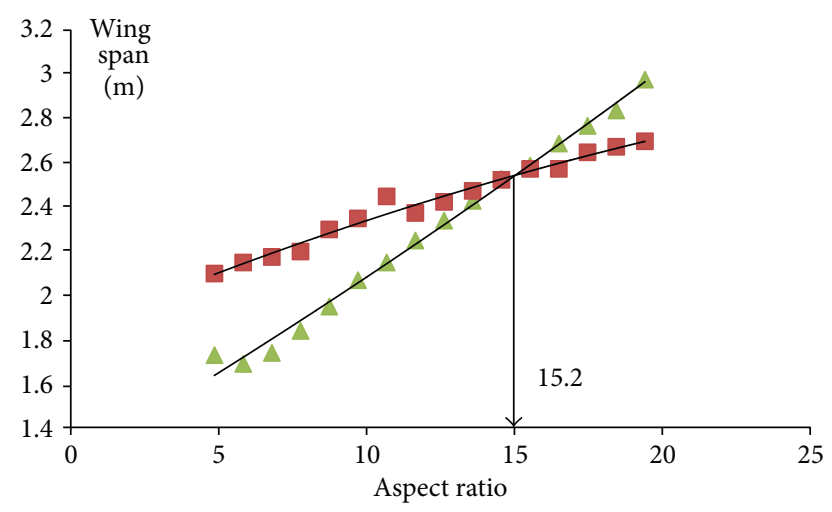

- Solar UAV

- Nonsolar UAV

FIGURE 5: Aspect ratio versus wing span of the solar and nonsolar UAVs at $0.35 \mathrm{~kg}$ payload.

ratio of 12 is plotted in Figure 4. These data also identified that the wing span of $2.55 \mathrm{~m}$ is suitable for both types of flights at an aspect ratio of 12 . This innovative design approach can be used to design and develop a single airframe structure suitable for both solar and nonsolar configurations.

The relationship between the wing span and aspect ratio at a constant payload of $0.35 \mathrm{~kg}$ is shown in Figure 5. The solar UAV configuration showed that the wing span increased more steeply than that of the nonsolar UAV configuration. This result is a clear sign of the structure rigidity issue. This issue is associated with the increase in wing span and decrease in wing chord to maintain the wing area. In this analysis criterion, the aspect ratio suitable for solar and nonsolar UAV configuration is 15.2. This value is fairly close to the aspect ratio of 16.4 that is suitable for the actual developed UAV [1], which was designed to carry a payload of $0.54 \mathrm{~kg}$ or $18 \%$ of the maximum take-off mass.

On a clear sunny day, approximately $55.5 \mathrm{~W}$ of the solar module power can be obtained per square meter wing area using an off-the-shelf $6 \%$ efficiency Powerfilm MP3-37 flexible solar cell specification at a constant aspect

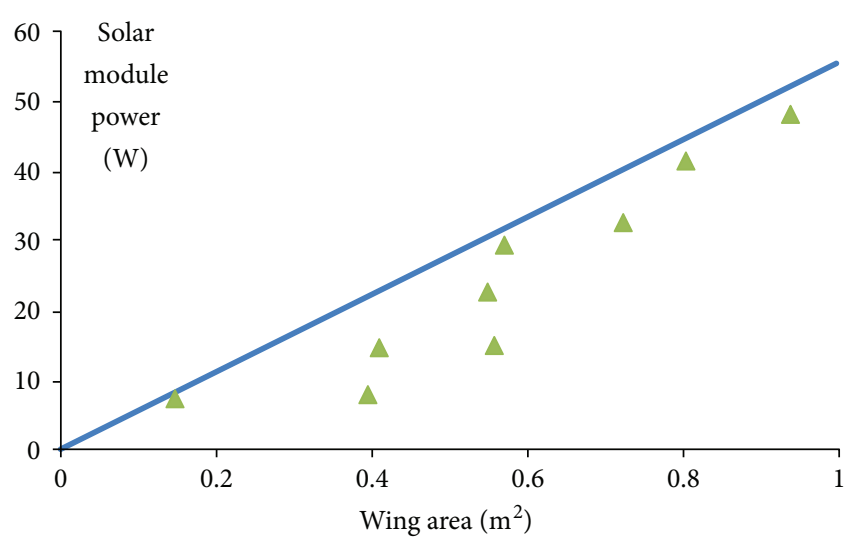

A Solar module power

- Solar module limit

FIgURE 6: Wing area versus solar module power of the solar UAVs.

ratio of 12 (Figure 6). However, only some of the points were close to the maximum achievable solar power (blue line in Figure 6). The issue may be resolved by performing further simulations with different aspect ratios to optimize the solar module power achieved in solar UAV sizing.

The relationship between the mass of the payload and battery of both solar and nonsolar UAVs (Figure 7) indicates that the mass of the battery gradually increases with payload. This result can be attributed to the minimum size of the battery pack, which comes in multiples of $150 \mathrm{~g} \pm$ $10 \%$. This finding proves another advantage of applying the electric propulsion modeling as part of this design modeling, where sizing small UAVs provides an accurate weight prediction.

The curve also shows that at a fixed wing area, the battery mass of the solar UAV is almost a third larger than that of the nonsolar UAV at $0.9 \mathrm{~kg}$ payload. This clearly shows that at $0.9 \mathrm{~kg}$ payload, the solar UAV wing is fully covered by the solar module. Therefore, the mass of the battery has to be increased to compensate the limitation with the area available for solar module placement and its weight addition to the overall maximum take-off mass.

Similarly, Figure 8 shows the relationship between the payload and the mass of the propulsion for both solar and nonsolar UAVs. In this figure, the curve shows that the propulsion mass of the solar UAV is higher by almost a third than that of the nonsolar UAV $(0.9 \mathrm{~kg}$ payload). This result clearly signifies the effect of propulsion mass which includes the propeller, electric motor, electronic speed controller, gear box, and propeller adapter at a specified payload.

The required power (total mission) for both solar and nonsolar UAVs as a function of maximum take-off mass is illustrated in Figure 9. Although the effect of the minimum battery pack mass can be observed for the low UAV mass, a smoother correlation is observed as the values increased. Again, this result can be attributed to the minimum size of the high-power-density lithium polymer cell, which comes in multiples of $50 \mathrm{~g} \pm 10 \%$. Since the system studied here operates at 3 battery cells in series, a minimum battery pack mass comes in multiples of $0.15 \mathrm{~kg}$. Thus at an aircraft mass 


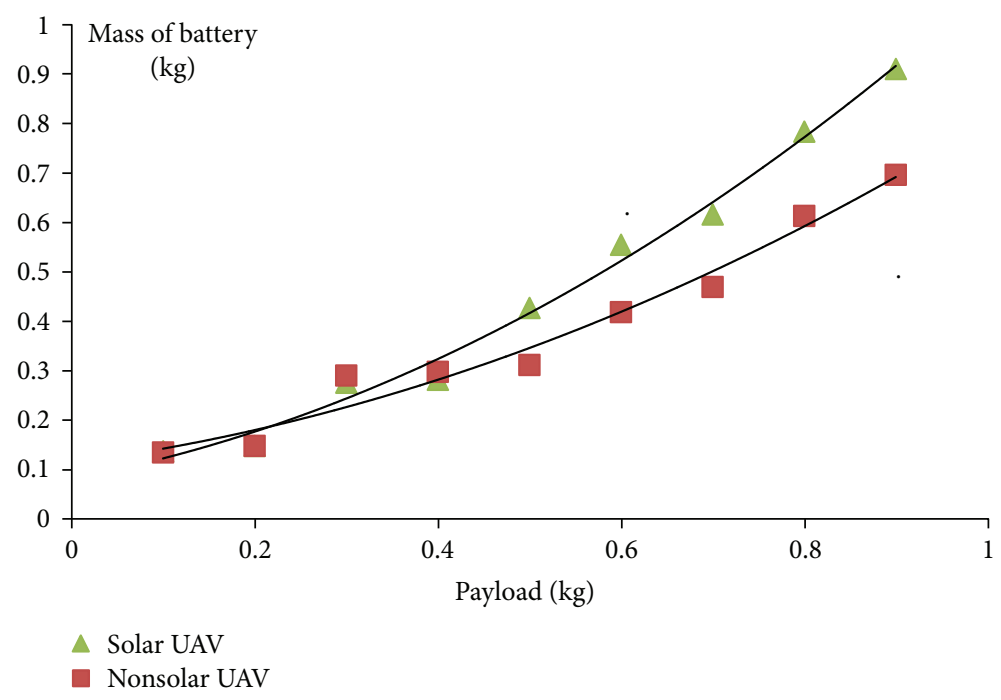

FIGURE 7: Mass of the payload versus battery of the solar and nonsolar UAVs.

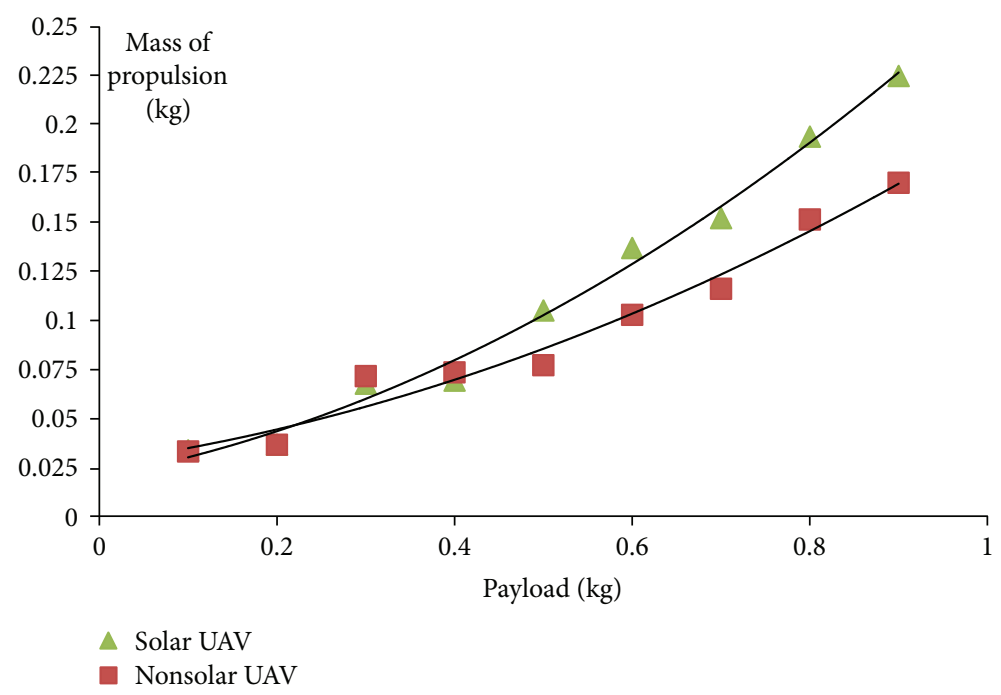

Figure 8: Mass of the payload versus propulsion of the solar and nonsolar UAVs.

of $1.5 \mathrm{~kg}$, the power consumption rises slowly due to the increase in the control and propulsion system.

This UAV design model estimates that a nonsolar UAV can only carry a maximum of $3 \mathrm{~kg}$ for a flight of 9 hours or only $0.1 \mathrm{~kg}$ for a flight of almost 23 hours at an aspect ratio of 12. However, a solar UAV that operates in Cranfield, UK, during the summer can fly for 24 hours and 9 hours with 0.1 and $1.3 \mathrm{~kg}$ payloads, respectively.

Currently, nonsolar UAVs can carry more payload at any particular time and place than solar UAVs, at a given endurance requirement. However, the principal weakness of nonsolar UAVs is their poor endurance. This weakness can be addressed using a solar UAV, which has a highendurance capability.

The choice of the electrically powered UAV type should be based on the technical requirements specified by the customer. A solar- and battery-powered electric UAV is preferred on missions that require flight durations of more than 24 hours regardless of the amount of payload it can carry. Otherwise, a battery-powered UAV may be opted for.

The needs of a solar-augmented battery-powered vehicle rather than of a battery-only flight vehicle must be evaluated carefully in terms of location and date of operation in the year. Determining the number of days a designed solar UAV engages in full operation is necessary for selecting the appropriate type of electrically powered flight vehicle. This simulation was conducted specifically for a UAV to be operated on a summer day in Cranfield. The developed solar irradiance submodel offers an efficient design optimization and customization process for various UAV operating locations.

The validation results of this study involve design modeling based on the three new and three improvised design properties that substantially improved the final UAV design 


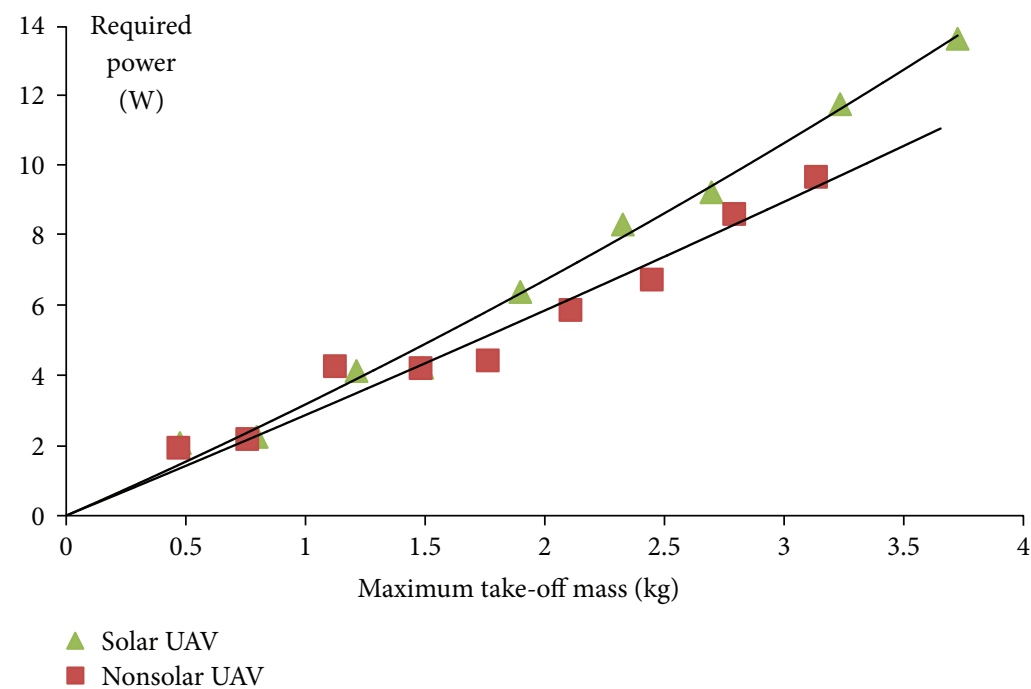

FIgURE 9: Maximum take-off mass versus required power of the solar and nonsolar UAVs.

TABLE 1: Comparison of current and previous small solar-powered UAV designs.

\begin{tabular}{|c|c|c|c|c|c|c|}
\hline Research UAV & Aircraft & Mass $(\mathrm{kg})$ & Wing span $(\mathrm{m})$ & Endurance (hr) & $\begin{array}{c}\text { Cruise } \\
\text { power }(W)\end{array}$ & $\begin{array}{c}\text { Power/take-off } \\
\text { mass }(\mathrm{W} / \mathrm{kg})\end{array}$ \\
\hline AcPropulsion & So Long & 12.8 & 4.75 & 48 & 95 & 7.42 \\
\hline Technion & Sun-Sailor & 3.6 & 4.2 & 11 & 40 & 11.11 \\
\hline $\begin{array}{l}\text { Swiss Federal Institute of } \\
\text { Technology of Zurich }\end{array}$ & Sky-Sailor & 2.4 & 3.2 & 27 & 15 & 6.25 \\
\hline $\begin{array}{l}\text { Swiss Federal Institute of } \\
\text { Technology of Zurich }\end{array}$ & Sun Surfer & 0.12 & 1 & - & 1.77 & 14.75 \\
\hline $\begin{array}{l}\text { Swiss Federal Institute of } \\
\text { Technology of Zurich }[10,11]\end{array}$ & AtlantikSolar AS-2 UAV & 6.93 & 5.65 & 28 & 39.7 & 5.73 \\
\hline University of Minnesota $[7,8]$ & SUAV:Q hybrid & 3.364 & 4 & 12 & 30 & 8.92 \\
\hline Cranfield University & Current work & 3 & 3.7 & 23.0 & 15 & 5.00 \\
\hline
\end{tabular}

characteristics and performance. Table 1 shows the comparison of all small solar-powered UAVs to the UAV designed using the current mathematical design model.

The UAV developed using the current design model had a $25 \%$ smaller ratio between power consumption and take-off mass than its closest competitor. Nevertheless, the AtlantikSolar AS-2 UAV design is a well-designed solarpowered UAV, yet the proposed design methodology may be used to further improve the design. This is because the power-to-mass ratio of the Cranfield Solar UAV is slightly better than that of AtlantikSolar AS-2 UAV. A detailed aircraft specification of the Cranfield Solar UAV is specified in Table 2.

The comparison further affirms the importance and need of the three new and three improvised design properties to optimize the UAV final design. The optimization of power and the propulsion system in UAVs based on the desired aircraft performance indicates that the new electric propulsion design properties are main contributors to the $25 \%$ reduction in the power consumption-to-take-off mass ratio. The overall enhancement of the developed mathematical design model ensures that the final UAV design is improved in all aspects of design optimization.

\section{Conclusion}

A comprehensive UAV mathematical design model with nine design properties was developed. This design model consists of three new aspects of design consideration and three improved design properties. This work substantially enhanced the final UAV design characteristics and performance for a high-endurance mission. Design validation showed a $25 \%$ smaller ratio between power consumption and take-off mass in the UAV designed using the current mathematical design model than in previous UAVs. Solar(solar and battery) and nonsolar- (battery-only) powered UAVs were also compared. The nonsolar UAV can carry more payload at any particular time and place than a solar $\mathrm{UAV}$, at a given endurance requirement. However, the endurance of a nonsolar UAV is its principal limitation. This feature can be addressed by using a solar UAV with a high-endurance performance. Payload has the highest effect on the maximum take-off mass, followed by the battery, structure, and propulsion mass. Ultimately, the type of an electrically powered vehicle to be selected will be in accordance with the technical requirements specified by the customer. 
TABLE 2: Cranfield solar UAV specification.

\begin{tabular}{lc}
\hline Description & Specification \\
\hline Wing airfoil & AG24, AG25, AG26 \\
Tail airfoil & HT21 \\
Length (m) & 1.8 \\
Wing span (m) & 3.7 \\
Wing aspect ratio & 16.4 \\
Wing area (dm ${ }^{2}$ ) & 83.6 \\
PowerFilm MP3-37 solar module area $\left(\mathrm{dm}^{2}\right)$ & 79.0 \\
Peak electric motor operating power (W) & 500 \\
Structure mass (kg) & 0.986 \\
Hacker X-40 Pro electronic speed & 0.050 \\
controller mass (kg) & \\
Hacker A30-14L electric motor \& & 0.160 \\
mounting mass (kg) & \\
13' $\times 8^{\prime}$ folding propeller \& propeller & 0.020 \\
adapter mass (kg) & \\
Eyecam 2.4 GHz micro wireless video & 0.050 \\
camera mass (kg) & \\
LC-18650-JP-2600 lithium-ion polymer & 1.050 \\
battery pack mass (kg) & \\
Futaba R617FS 7-channel 2.4 GHz receiver & 0.010 \\
mass (kg) & 0.044 \\
Hitec HS-85MG Servos mass (kg) & 0.200 \\
Eagle Tree inboard system mass (kg) & 0.030 \\
Connector \& wire mass (kg) & 0.400 \\
Total solar module mass (kg) & 3.0 \\
Take-off mass (kg) & \\
\hline
\end{tabular}

\section{Nomenclature}

$\begin{array}{ll}W_{\text {TOmax }}: & \text { Maximum take-off weight (N) } \\ W_{\text {Struct }}: & \text { Structure weight (N) } \\ W_{\text {Empty }}: & \text { Empty weight (N) } \\ W_{\text {Solar }}: & \text { Solar power system weight (N) } \\ W_{\text {Batt }}: & \text { Battery weight (N) } \\ W_{\text {Ctrl }}: & \text { Control system weight }(\mathrm{N}) \\ W_{\text {Pay_Max }}: & \text { Maximum payload weight (N) } \\ \text { eff } f_{\text {Electric }}: & \text { Electric propulsion system efficiency (\%) } \\ b: & \text { Wing span (m) } \\ c: & \text { Mean aerodynamic chord length (m) } \\ C_{\text {Lmax_W }}: & \text { Wing maximum lift coefficient } \\ C_{\text {Mo_HT }}: & \text { Tail zero-lift-pitching moment coefficient } \\ S_{\text {Cell }}: & \text { Number of battery cells in series in a battery } \\ Q_{\text {Cell }}: & \text { pack } \\ P_{\text {Cell }}: & \text { Battery cell's capacity (A/hr) } \\ V_{\text {maxCell }}: & \text { Number of battery cells in parallel in a battery } \\ t_{\text {Daylight }}: & \text { Battery cell's maximum voltage (V) } \\ \text { DN: } & \text { Flight duration with daylight (hr) } \\ C_{\text {Mo: }}: & \text { Day number } \\ C_{\text {Mo_W }}: & \text { Aircraft zero-lift-moment coefficient } \\ V: & \text { Wing zero-lift-moment coefficient } \\ l_{\mathrm{HT}}: & \text { Airspeed (m/s) } \\ & \text { Tail moment arm (m) }\end{array}$

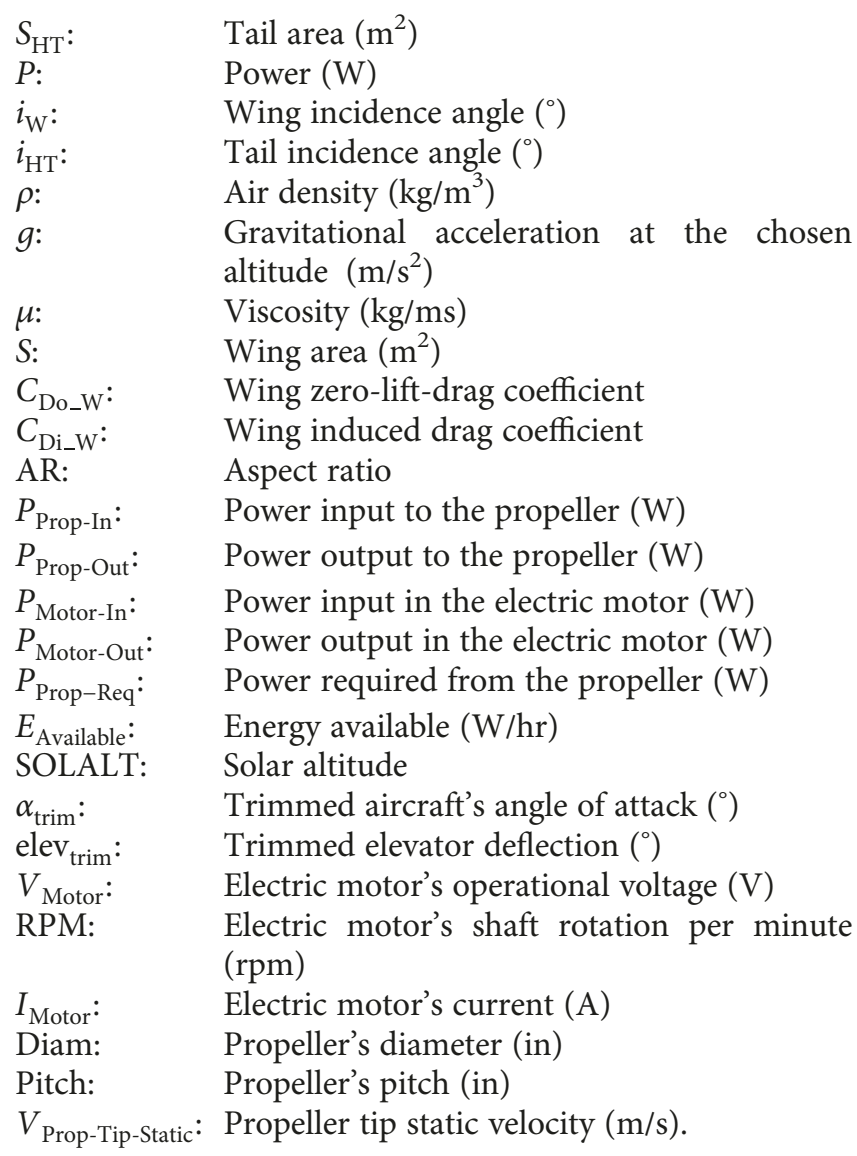

\section{Conflicts of Interest}

The authors declare no conflict of interest.

\section{Authors' Contributions}

Parvathy Rajendran and Howard Smith conceived and designed the experiments, Parvathy Rajendran performed the experiments, Parvathy Rajendran and Howard Smith analyzed the data, and Parvathy Rajendran and Howard Smith wrote the paper.

\section{Acknowledgments}

This publication was supported by Universiti Sains Malaysia Grant no. 304/PAERO/6315002.

\section{References}

[1] P. Rajendran and H. Smith, "The development of small solar powered electric unmanned aerial vehicle systems," in $4 \mathrm{TH}$ International Conference on Mechanical and Manufacturing Engineering 2013 (ICME2013), Applied Mechanics and Materials (ISI), Bangi, Selangor, 2013.

[2] H. M. G. Vidales, Design, Construction and Test of the Propulsion System of a Solar UAV, MSc, Aerospace Engineering, Technical University of Lisbon, Lisbon, Portugal, 2013.

[3] M. R. Bhatt, Solar Power Unmanned Aerial Vehicle: High Altitude Long Endurance Applications (HALE-SPUAV), San Jose State University, San Jose State, 2012. 
[4] S. Cowley, Solar Powered UAV, In NASA Tech Briefs 2013, New York, 2013.

[5] P. Rajendran and H. Smith, "Review of the battery \& solar power system development of small solar powered electric unmanned aerial vehicles," Advance Materials Research, vol. 1125, pp. 641-647, 2014.

[6] P. Rajendran and H. Smith, "Review of the elementary aspect of solar-powered electric unmanned aerial vehicles," Australian Journal of Basic and Applied Sciences, vol. 8, pp. 252-259, 2014.

[7] R. D'Sa, D. Jenson, and N. Papanikolopoulos, "SUAV: Q-a hybrid approach to solar-powered flight," in 2016 IEEE International Conference on Robotics and Automation (ICRA), pp. 3288-3294, Stockholm, Sweden, May 2016.

[8] S. Morton and N. Papanikolopoulos, "Two meter solar UAV: Design approach and performance prediction for autonomous sensing applications," in 2016 IEEE/RSJ International Conference on Intelligent Robots and Systems (IROS), pp. 16951701, Daejeon, South Korea, October 2016.

[9] S. Morton, L. Scharber, and N. Papanikolopoulos, "Solar powered unmanned aerial vehicle for continuous flight: conceptual overview and optimization," in 2013 IEEE International Conference on Robotics and Automation, pp. 766-771, Karlsruhe, Germany, May 2013.

[10] P. Oettershagen, A. Melzer, T. Mantel et al., "A solar-powered hand-launchable UAV for low-altitude multi-day continuous flight," in 2015 IEEE International Conference on Robotics and Automation (ICRA), pp. 3986-3993, Seattle, WA, USA, May 2015.

[11] P. Oettershagen, A. Melzer, T. Mantel et al., "Perpetual flight with a small solar-powered UAV: flight results, performance analysis and model validation," in 2016 IEEE Aerospace Conference, Big Sky, MT, USA, March 2016.

[12] N. Diepeveen, "The Sun-Surfer: design and construction of a solar powered MAV," Autonomous Systems Lab, Swiss Federal Institute of Technology in Zurich, Switzerland, 2007.

[13] A. Noth, W. Engel, and R. Siegwart, "Design of an ultralightweight autonomous solar airplane for continuous flight," Proceedings of Field and Service Robotics, Port Douglas, Australia, 2005.

[14] A. Noth, "Design of solar powered airplanes for continuous flight," ETH, Zurich, Switzerland, 2008.

[15] A. Noth, "Sky-Sailor solar powered airplane proved continuous flight," 2008.

[16] P. Rajendran, "Investigation in to the design space associated with electrically powered flight vehicles," Cranfield University, Cranfield, UK, 2012.

[17] T. C. Tozer, D. Grace, J. Thompson, and P. Baynham, "UAVs and HAPs-potential convergence for military communications," in IEE Colloquium on Military Satellite Communications (Ref. No. 2000/024), London, UK, June 2000.

[18] K. Valavanis, Advances in Unmanned Aerial Vehicles: State of the Art and the Road to Autonomy, vol. 33, Springer Science \& Business Media, Berlin, Germany, 2008.

[19] O. K. Sahingoz, "Generation of bezier curve-based flyable trajectories for multi-UAV systems with parallel genetic algorithm," Journal of Intelligent \& Robotic Systems, vol. 74, no. 1-2, pp. 499-511, 2014.

[20] A. Noth, "Design of solar powered airplanes for continuous flight," In Swiss Federal Institute of Technology of Zurich, Switzerland, 2006.
[21] J. D. Anderson, Introduction to Flight, McGraw Hill, New York, USA, 2005.

[22] T. Mueller, J. Kellogg, P. Ifju, and S. Shkkarayev, Introduction to the Design of Fixed-Wing Micro Air Vehicles, American Institute of Aeronautics and Astronautics Inc, Reston, Virginia, USA, 2006

[23] T. Muneer, C. Gueymard, H. Kambezidis, and T. Muneer, Solar Radiation and Daylight Models, Elsevier Butterworth Heinemann: Oxford, Burlington, MA, USA, 2nd edition, 2004.

[24] T. Muneer and H. Kambezidis, Solar Radiation and Daylight Models for the Energy Efficient Design of Buildings, Architectural Pres, Oxford, 1997.

[25] P. Rajendran and H. Smith, "Implications of longitude and latitude on the size of solar-powered UAV," Energy Conversion and Management, vol. 98, pp. 107-114, 2015.

[26] P. Rajendran, H. Smith, and H. bin Masral, "Modeling and simulation of solar irradiance and daylight duration for a high-power-output solar module system," Applied Mechanics and Materials, vol. 629, pp. 475-480, 2014.

[27] P. Rajendran and H. Smith, "Modelling of solar irradiance and daylight duration for solar-powered UAV sizing," Energy Exploration \& Exploitation, vol. 34, no. 2, pp. 235-243, 2016.

[28] K. Sherwin, Man-Powered Flight, In Modell\& Allied Publications Ltd, Hertfordshire, UK, 1971.

[29] P. Rajendran, H. Smith, K. I. Yahaya, and N. M. Mazlan, "Electric propulsion system sizing for small solar-powered electric unmanned aerial vehicle," International Journal of Applied Engineering Research, vol. 11, pp. 9419-9423, 2016. 


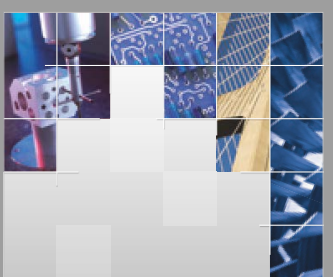

\section{Enfincering}
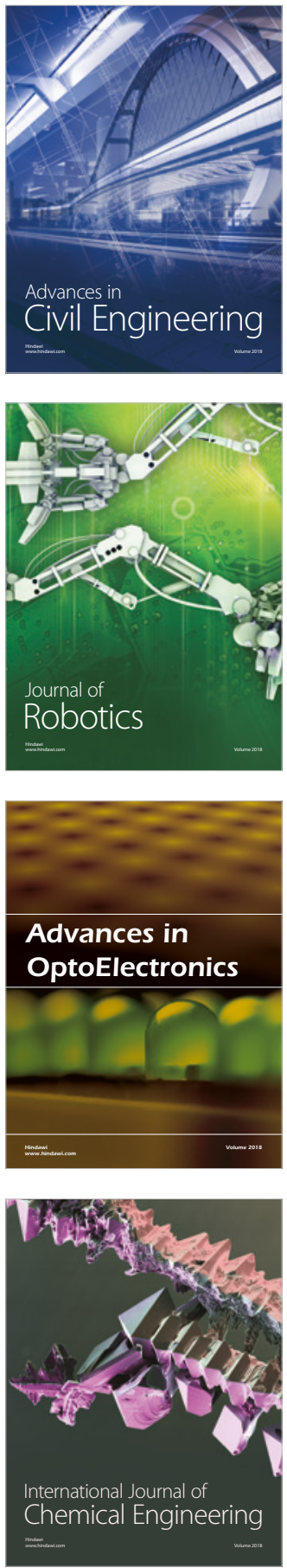

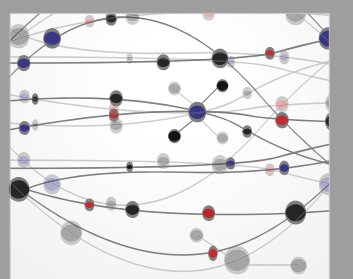

\section{Rotating \\ Machinery}

The Scientific World Journal

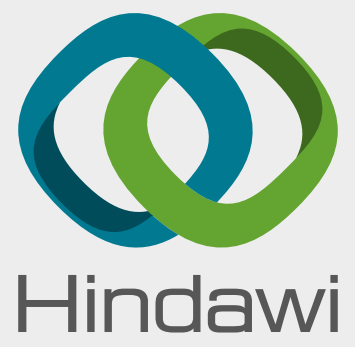

Submit your manuscripts at

www.hindawi.com
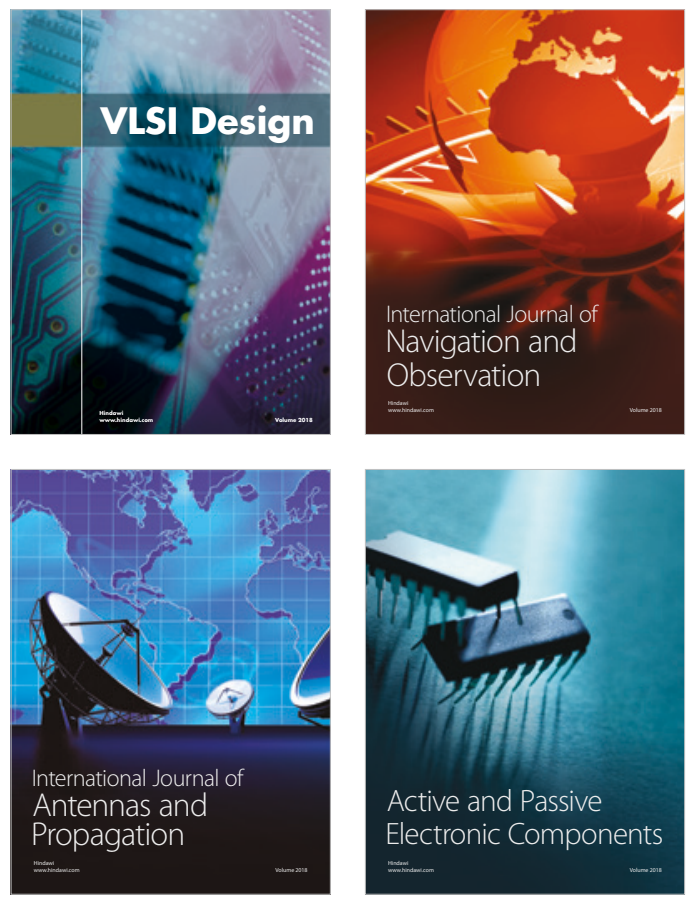
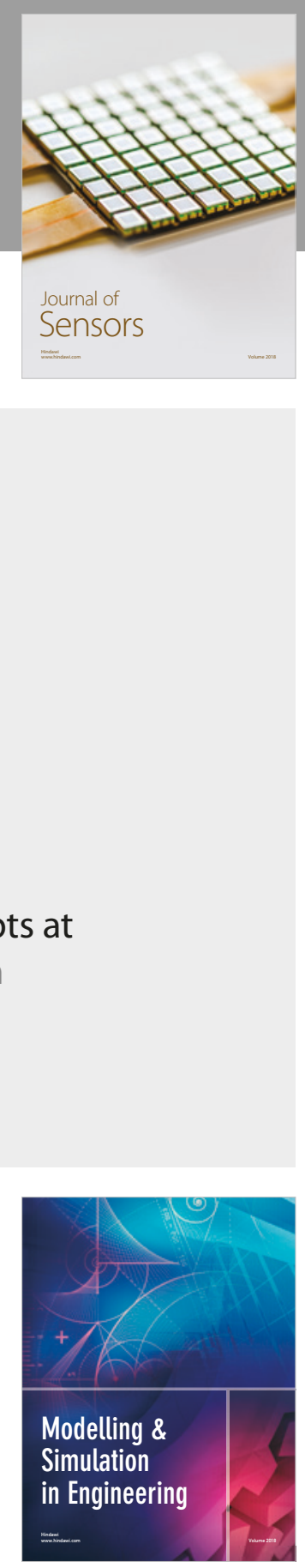

\section{Advances \\ Multimedia}
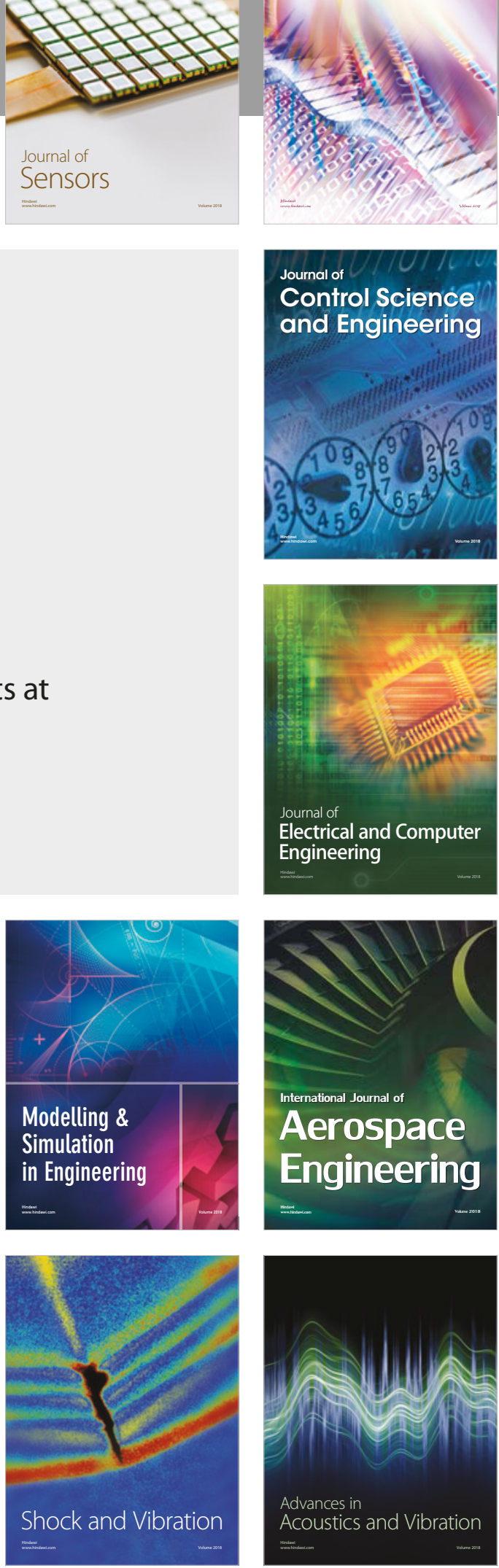